\title{
sciendo
}

\section{Internet of Things in Romanian agriculture}

\author{
Maria GIRIP \\ Bucharest University of Economic Studies, Bucharest, Romania \\ maria.girip@gmail.com \\ Daniela MARACINE \\ Bucharest University of Economic Studies, Bucharest, Romania \\ maracine.danielaa@gmail.com
}

\begin{abstract}
The latest technological discoveries in communication have translated into a more advanced and performant agriculture field which now has a greater online presence than ever before. Therefore, the new challenges to be faced in agriculture are not only the environmental ones, as it was in the past, where the weather was the variable having a higher power. The new challenge is raised by a fully technologized world. This paper is planning to analyze how agriculture changed in Romania after the internet and the online world. This also strives to highlight the main challenges faced by agriculture in the century of technology, its benefits and to answer the most asked question of the 21 st century. Is this version of agriculture the better or the healthier one? As for the wealth coming from the big progress, the data from Meticulous Research's report published in 2020 shows that the agriculture IoT market will reach 34.9 billion dollars by 2027. Meaning a significant raise of crops after industrialization, as well as a higher rate of profitability compared to past centuries and past technology phases. This means not only that farmers have better results, but their wealth has also grown, however, the main question still stands. The disadvantages come from its new own qualities - increased range of production, higher knowledge share, and industrialization.
\end{abstract}

Keywords: agriculture, Internet of Things (IoT), precision agriculture, technology.

\section{Introduction}

The current century has many technological breakouts, being called the century of tech - IT. Since the appearance of the internet - more than twenty years ago agriculture has had its share of development, from farmers using social media to connect with each other and share ideas, projects, advice, and even more. The other breakthroughs were the finest crop-producing achievements like High flexibility tiers, mapping via GPS, soil and crop sensors, precision devices - that lead to a new branch of agriculture - precision agriculture or PA (Benoit et al., 2012). With the help of mobile devices and years of study, the standardization process became a part of precision agriculture, and with the help of the internet and technology, this just made it more quantifiable. In $2016^{\text {th }}$ matioere were more than 7.25 billion mobile devices, compared to approximately 7.2 billion people. The numbers today are even higher - estimated to be 14.02 billion devices (O'Dea, 2020).

\section{What it is - The Internet of things?}

In agriculture, the internet of things or IOT is a broad range of new emerging technologies. Those technologies help with gathering data and measuring it, this data being accessed by farmers remotely via Cloud storage services. What was one's job, to go and take measurements of the humidity level is now provided by a sensor. An example of the information that can be collected is soil moisture, level of chemicals, dam levels, and livestock health - as well as monitor fences vehicles, and weather (Tzounis et al., 2017). The Internet of Things is a class of things, containing devices, technology, software, and a broad range of internet-powered solutions, in this case for 
agriculture. This paper will present the most important breakthroughs regarding the Internet of Things in agriculture and will try to argue the use case for every single one of them. As the world and not only agriculture changes with the advancement of the technology and software industry, but this paper will also address the concerns, the arguments for using new technology and try to highlight the differences and perks to it. The ability of farmers to modernize may be the way to overcome the current food crisis and environmental changes as the technologies listed below are trying to pursue a wasteless model of the business whilst respecting the environment and being sustainable.

\section{Precision agriculture $-P A$}

In precision agriculture is many processes and technology that work together to harvest the best possible outcome, this paper will share the first ten that had an impact on success. In 1990 agriculture gained access to satellites and the nickname - satellite agriculture. The concept was first seen in the US in the early 1980s after the research from Minnesota University applied a fixed grid sample - and the practice of grid sampling appeared. Nowadays is a four-stage process that implies spatial variability - Data collection, variables, strategies, implementing processes.

The use of GPS - Global positioning system enables farmers to go to specific locations to collect soil and crop samples. The mapping process is very helpful with own's land boundaries, irrigation - a farmer not only knows where the water is needed but can harvest data and see the improvement after irrigation. Below is an image gathered by Daedalus sensor Maricopa Agricultural Center in Arizona. The first sequence shows lush vegetation - with green and blue, red meaning barren soils.

In the second sequence, the green and blues shown, are reflecting the humidity - wet soil. Whilst red is dry soil. Stress is shown with yellow and red pixels (last sequence). (Earth Observatory Nasa, Images courtesy Susan Moran, Landsat 7 Science Team and USDA Agricultural Research Service). A concrete example is John Deere one of the biggest entrepreneurs in the domain of agriculture machinery, that has begun connecting tractors to the Internet and having them driven by GPS. The same company pioneers and the self-driving tractors would free the farmers from the burden of driving, reducing the need for human hands, and paving the future for better jobs in mechanization, agriculture digitalization, sustainability, eco-tractors, and so on. 


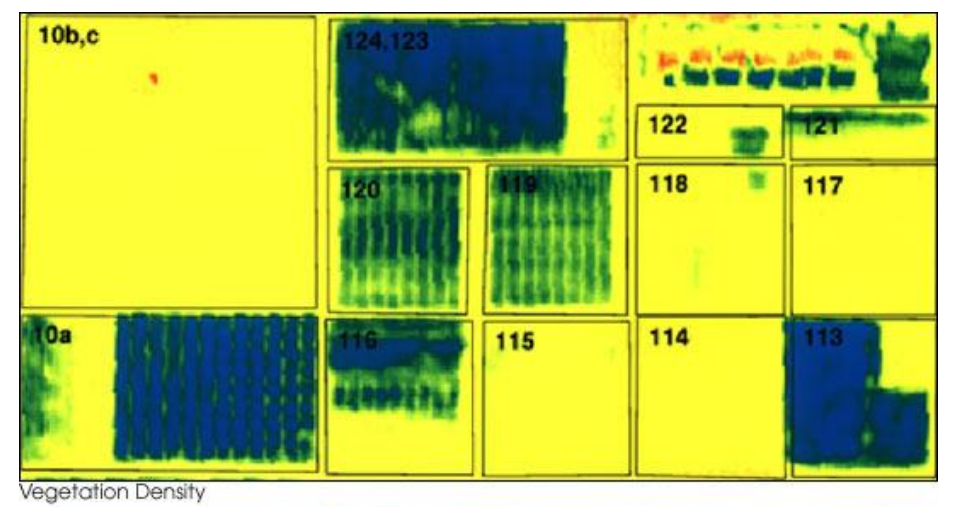

PICBE |

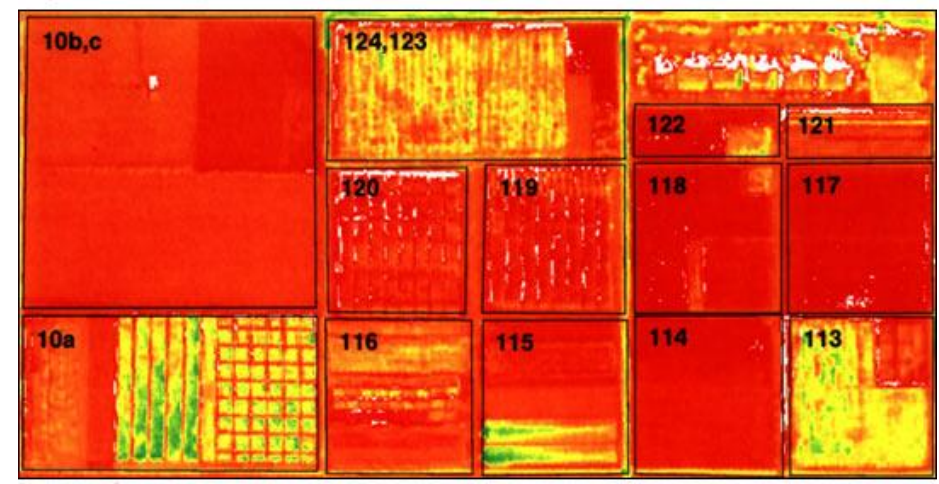

Water Deficit

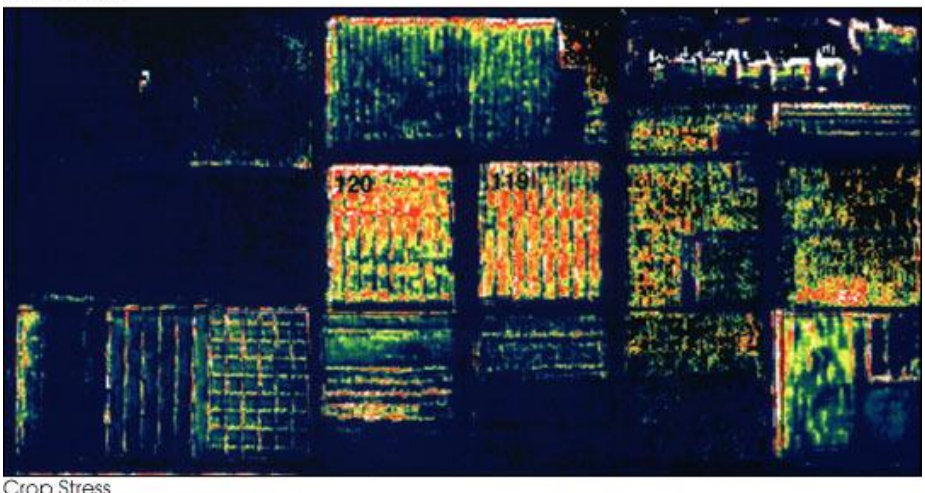

Figure 1. Precision farming

Source: (Earth Observatory Nasa) https://earthobservatory.nasa.gov/images/1139/precision-farming).

\section{Robotics}

Self-driving tractors, where the farmer steps in, emergency cases only - this is a breakthrough in technology, the new concept of a driverless tractor was presented at a dealer meeting in Spain.

The model should have zero emissions.

\section{Drones and satellite imagery}

Drones are used for high-quality images, surveillance, real-time data collection, while satellite imagery is used for the bigger picture. With the help of those - all variables needed for machine learning - and the software that standardizes can be easily gathered. In 2016 the shipment of consumer drones was estimated at 7 million and is on its path to reaching 29 million in 2021 . The ability of drones to rapidly-produce 3D maps cheaply makes them very important for the design of seed planting patterns. They are not only used for imagery purposes but also for carrying loads to 
spraying the plants, planting, observing, and so on, a report from the European Council states. (EC Europe, 2018). As for the satellite imagery, the cost of the classic ones - retrieved from satellites is expensive compared to drones, the second advantage of drones is that you do not need to order the images in advance and are more precise due to more control, with drones the data can be collected whenever is needed. Tracking of the changes in crops can also be done with the help of drones, gathering information such as the health and maturity of the crops is just one of the many features. Another use for drones is irrigation, agriculture being the biggest consumer of water in the world, almost 70\%, the same report from European Council states. As it is well known, the waste of excessive water usage is another problem Internet of Things and technology tries to tackle with its monitoring sensors and data analysis. Drones equipped with sensors can be a real helper in this area, as they can collect data about "hydric stress" with their thermal and infrared sensors. This way, a farmer can see in real-time which crops need more water and which do not, so they can adjust timely, whereas using the old technology, the water was used and distributed the same for all areas and not need-based (EC Europe, 2018).

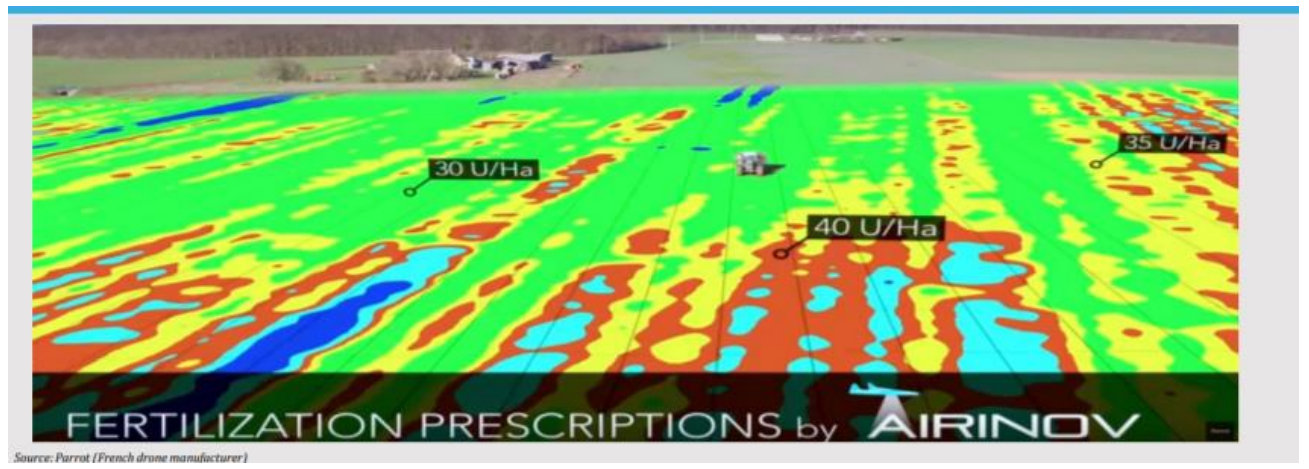

Figure 2. Visualization of data based on drone imagery

Source: EC Europe, 2018.

\section{Machine learning}

Machine learning is the system that allows a machine to learn a pattern and then predict future behaviors. The idea is simple, you give the rules of the data, how it spawns, then the machine will learn it and provide an algorithm. The author Padwick (2020) and his technology help with solutions in agriculture. Weed detection algorithms are a new breakthrough that will provide more and more precision and a healthier yield. Having the data collected and analyzed, prediction models can be drawn as in figure 3 below. The robot in this case sprays only the weeds. This is succeeded with a machine that drives through the field, and high-resolution cameras collect imagery. Then the convolutional neural network helps to analyze with PyTorch each frame. After this, a map is produced. The whole process takes only a few milliseconds (Padwick, 2020). 


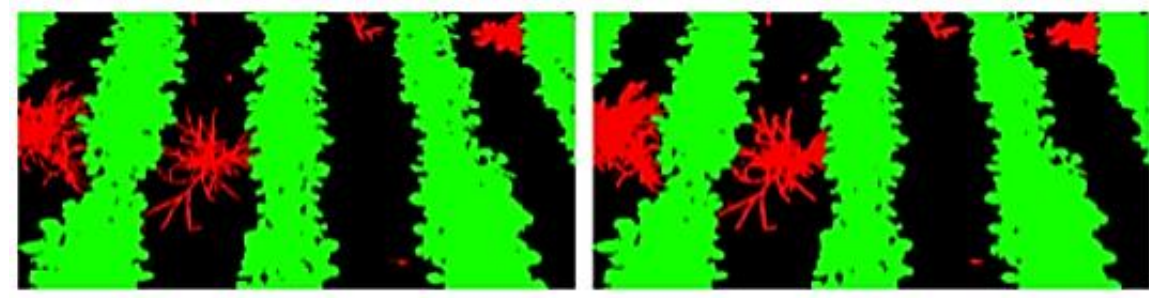

Label

Prediction

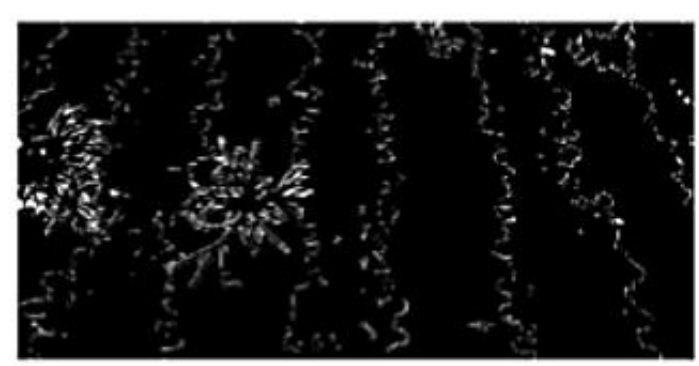

\section{Difference}

Figure 3. Prediction model for weeds

Source: Padwick Chris - Director of Computer Vision and Machine Learning at Blue River Technology.

\section{Smartphone applications}

At the current time, the need for resources - the food issue is not new. Along with other problems, like consumerism, pollution, soil degradation, water depletion, the news of sustainable choices is the perfect way for new technology to grow. The introduction of mobile technologies, portable devices, and so on, led to new innovative services that are used within the agricultural field. A direct correlation between developed countries and their level of technology shows that with a higher level of technology comes a smaller need for the human workforce. The use of mobile apps and cloud computing is related to optimization of the fertilizer seeds, water, and so on. Farmers can manage those via mobile applications. This way, having real-time data, money can be saved, and waste reduced. The Agricultural Research Service (ARS) released two apps - "LandInfo" and "LandCover", currently just for Android phones. These apps connect entrepreneurs worldwide and help them share knowledge on how to maximize their productivity while conserving resources (Sourcetrace, 2020).

To further demonstrate the use of IoT, machine learning, devices, data science $\&$ analysis in production the scheme below was drawn - figure 4.

With blue is IoT - Internet of things, the concept explained above. With the help of this and sensors from devices, either mobile devices or not, the gathering of data happens. The raw data flows into a database where with the help of machine learning and data science \& analysis the variation data model is read and optimized to obtain the desired results.

The chosen optimization will then flow through implementation, manually or automated (depending on the level of automatization) on the manual one, the farmer should make the inputs based on the information received from the software vs the fully automated one will deliver the necessary information to the devices - the irrigation systems etc. 


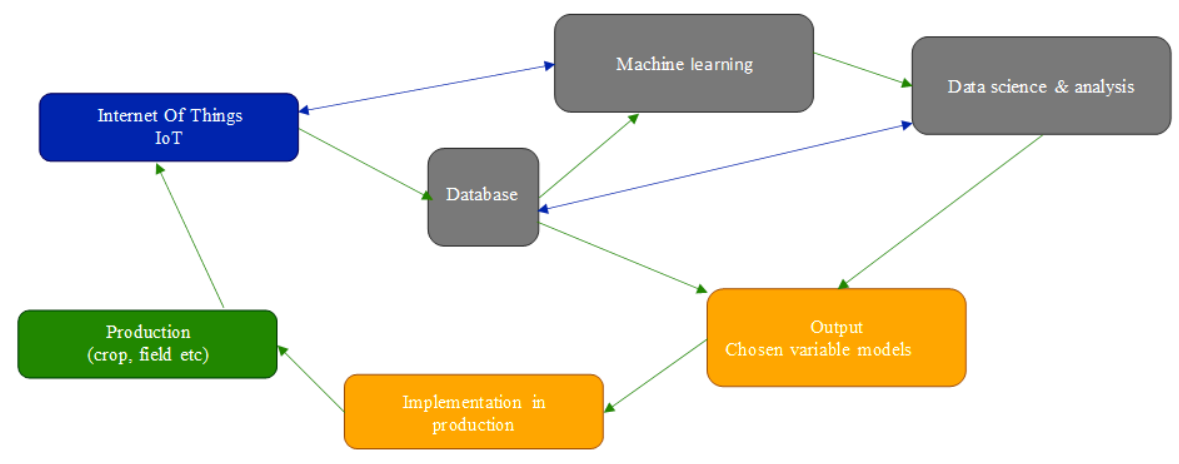

PICBE |

Figure 4. Internet of Things scheme

Source: Authors' own research.

\section{Social media and knowledge share}

More to this, and one of the things that this paper approaches, is the wide knowledge that now can be shared, a global approach that shows people can now find what suits them best based on other experiences. What was a library, hard to understand knowledge now is available to use by anyone that needs it. Studies are no longer necessary to gain experience but only a click away you can find others' own experience both written and video, and the most important - real-time data. In the past, information was in books and most of the time was hardly accessible by regular people, specialty literature was not broadly available and most of the time the information was outdated. Now entrepreneurs have the means to gather real-time data, share with their fellow groups and members what they know, apply proven methods given by people that went or are going through the same situations as them (Dermody, 2013).

\section{Literature review}

\section{Current situation in Romania}

At present, the literature review for the chosen subject in Romania is brief. As Zarnescu (2019) states, Romania is showing interest in IoT agriculture. The company Syswins Solution covers 38,000 ha in Romania. They use their monitoring solution via IoT in Cerealcom to gather data for soil water's reserves, microclimates due to climate changes and weather changes. This helps farmers to know at least a few hours before bad weather or unpleasant changes storm in Dolj. (Zarnescu, 2019) As for the national and international approach of the subject, the authors Tzounis A., Katsoulas $\mathrm{N}$ et al. states, internet and online brought a new challenge with its more than a dozen advantages, from afar the most important one - access to knowledge and its power of sharing, whilst $\mathrm{W}$ states that fast farming using technology and the internet favor an unhealthy lifestyle. Previously it was argued by Willett \& Stampfer in 2013 that slow food - from producing it to preparing it has numerous benefits on human health. In Romania, the rate of digital skills is still the lowest in Europe a study from Eurostat shows. Only 10\% of the population has superior digital skills. The same study shows that $43 \%$ of Romanians with age between 16-74 years have low digital skills. Although the companies are a real help to the consumer/client in terms of user experience (UX), digital skills are still needed for the ones that strive for more. Having the data is not enough, but learning from it, and drawing future predictions, establishing patterns is a must when talking about the roadmap to success. 
Table 1. Individuals who have low overall digital skills

\begin{tabular}{|c|c|c|c|c|}
\hline Individuals who have low overall digital skills & $\begin{array}{r}2015 \\
(\%)\end{array}$ & $\begin{array}{l}2016 \\
(\%)\end{array}$ & $\begin{array}{l}2017 \\
(\%)\end{array}$ & $\begin{array}{l}2019 \\
(\%)\end{array}$ \\
\hline Belgium & 24 & 25 & 27 & 29 \\
\hline Bulgaria & 25 & 33 & 34 & 38 \\
\hline Czechia & 23 & 28 & 24 & 24 \\
\hline Denmark & 20 & 19 & 26 & 27 \\
\hline Germany (until 1990 former territory of the FRG) & 21 & 22 & 22 & 22 \\
\hline Estonia & 23 & 26 & 27 & 28 \\
\hline Ireland & 35 & 37 & 33 & 36 \\
\hline Greece & 22 & 23 & 23 & 24 \\
\hline Spain & 23 & 25 & 28 & 31 \\
\hline France & 28 & 29 & 29 & 32 \\
\hline Croatia & 18 & 17 & 25 & 26 \\
\hline Italy & 21 & 23 & & 32 \\
\hline Cyprus & 28 & 32 & 29 & 41 \\
\hline Latvia & 29 & 29 & 33 & 42 \\
\hline Lithuania & 20 & 22 & 22 & 25 \\
\hline Luxembourg & 11 & 11 & 12 & 30 \\
\hline Hungary & 23 & 28 & 27 & 31 \\
\hline Malta & 23 & 27 & 23 & 29 \\
\hline Netherlands & 20 & 17 & 16 & 16 \\
\hline Austria & 19 & 18 & 19 & 21 \\
\hline Poland & 27 & 28 & 28 & 35 \\
\hline Portugal & 20 & 22 & 23 & 22 \\
\hline Romania & 29 & 32 & 35 & 43 \\
\hline Slovenia & 21 & 21 & 24 & 28 \\
\hline Slovakia & 24 & 25 & 22 & 29 \\
\hline Finland & 18 & 20 & 18 & 19 \\
\hline Sweden & 17 & 24 & 18 & 24 \\
\hline Iceland & & & 13 & 13 \\
\hline Norway & 17 & 22 & 21 & 16 \\
\hline Switzerland & & & 17 & 19 \\
\hline United Kingdom & 24 & 25 & 23 & 20 \\
\hline Montenegro & & & 22 & \\
\hline North Macedonia & 33 & 38 & 42 & 50 \\
\hline Albania & & & & 47 \\
\hline Serbia & 33 & & 31 & 31 \\
\hline Turkey & 27 & 29 & 30 & 37 \\
\hline Bosnia and Herzegovina & & & & 46 \\
\hline $\begin{array}{l}\text { Kosovo (under United Nations Security Council Resolution } \\
\text { 1244/99) }\end{array}$ & & & 62 & 59 \\
\hline
\end{tabular}

PICBE |

Source: Eurostat Individuals' level of digital skills.

DOI: 10.2478/picbe-2021-0053, pp. 570-583, ISSN 2558-9652 |

Proceedings of the $15^{\text {th }}$ International Conference on Business Excellence 2021 
As it is shown in the table above, most of Europe's countries have a percentage of individuals with low overall digital skills below 35\%. Romania is at the bottom of the ranking with $43 \%$. This is close to saying that more than half of the population in Romania does not have basic digital skills. The percent of the population over 50 years old $(33 \%)$ is more than the percent of the population under 24 years old, as the data from Eurostat shows in the figure below (EC Europe, 2020). The population that is working in agriculture in Romania is $30 \%$. Correlated with the data of digitalized population, the conclusion here is that the digitalized working population in agriculture is also low. Another constraint that must be taken into consideration is that in Romania, $86 \%$ of the farms are consumers for more than $50 \%$ of their final productions, compared to other states where the average is around $20 \%$.

Table 2. Farm indicators by agricultural area, type of farm, standard output, sex and age of the manager

\begin{tabular}{|c|c|c|c|}
\hline Country & $\begin{array}{l}\text { Farm - } \\
\text { number }\end{array}$ & $\begin{array}{c}\text { Farms whose } \\
\text { household consumes } \\
\text { more than } 50 \% \\
\text { of the final } \\
\text { production - number }\end{array}$ & $\begin{array}{c}\text { Percentage } \\
\text { of the farms } \\
\text { whose } \\
\text { household } \\
\text { consumes }\end{array}$ \\
\hline Belgium & 36,890 & - & $0 \%$ \\
\hline Bulgaria & 202,720 & - & $0 \%$ \\
\hline Czechia & 26,530 & 4,120 & $16 \%$ \\
\hline Denmark & 35,050 & - & $0 \%$ \\
\hline Germany (until 1990 former territory of the FRG) & 276,120 & - & $0 \%$ \\
\hline Estonia & 16,700 & 4,900 & $29 \%$ \\
\hline Ireland & 137,560 & - & $0 \%$ \\
\hline Greece & 684,950 & 109,600 & $16 \%$ \\
\hline Spain & 945,020 & 33,400 & $4 \%$ \\
\hline France & 456,520 & 7,040 & $2 \%$ \\
\hline Croatia & 134,460 & 70,130 & $52 \%$ \\
\hline Italy & $1,145,710$ & 289,880 & $25 \%$ \\
\hline Cyprus & 34,940 & 19,560 & $56 \%$ \\
\hline Latvia & 69,930 & 27,160 & $39 \%$ \\
\hline Lithuania & 150,320 & 67,430 & $45 \%$ \\
\hline Luxembourg & 1,970 & - & $0 \%$ \\
\hline Hungary & 430,000 & 257,100 & $60 \%$ \\
\hline Malta & 9,210 & 2,630 & $29 \%$ \\
\hline Netherlands & 55,680 & - & $0 \%$ \\
\hline Austria & 132,500 & - & $0 \%$ \\
\hline Poland & $1,410,700$ & 259,000 & $18 \%$ \\
\hline Portugal & 258,980 & 108,380 & $42 \%$ \\
\hline Romania & $3,422,030$ & $2,956,380$ & $86 \%$ \\
\hline Slovenia & 69,900 & 40,150 & $57 \%$ \\
\hline Slovakia & 25,660 & 15,800 & $62 \%$ \\
\hline Finland & 49,710 & - & $0 \%$ \\
\hline Sweden & 62,940 & - & $0 \%$ \\
\hline United Kingdom & 185,060 & - & $0 \%$ \\
\hline
\end{tabular}

Source Eurostat: Farm indicators by agricultural area, type of farm, standard output, sex and age of the manager and NUTS 2 regions. 


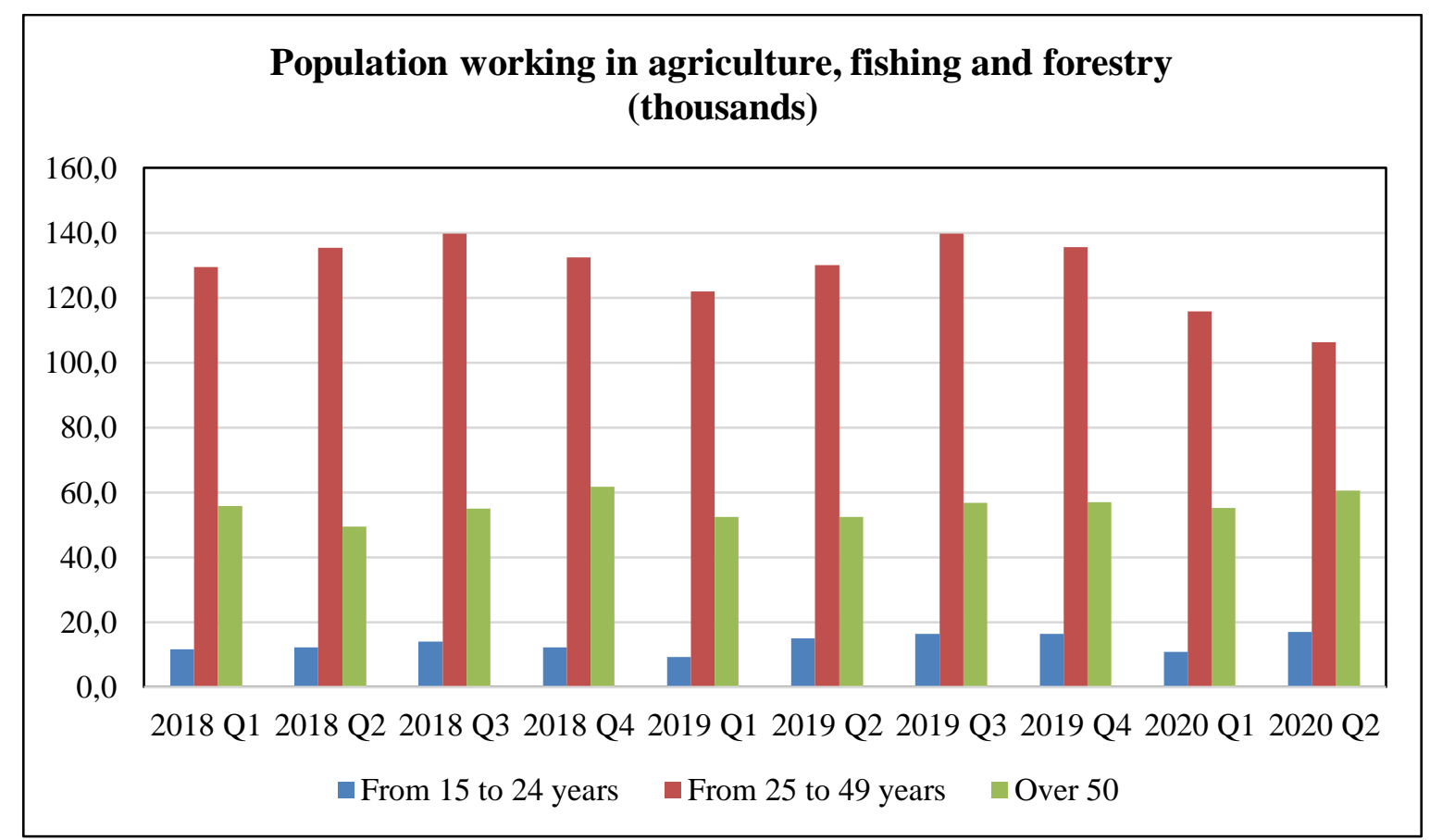

PICBE | 578

Figure 5. Population working in agriculture, fishing and forestry

Source: Eurostat Employees by sex, age and economic activity (from 2008 onwards, NACE Rev. 2) - 1000.

As many conclude, agriculture should benefit from the advantages of the new tech era but should strive to produce better quality, the focus must shift from the profit. The current challenges are the ones provided by external sources as climate changes, drought phenomena, food crisis, and so on. But no less important are the internal ones, closer rather to human resistance towards change and new technology, some of the constraints being: lack of knowledge and digital skills, the older population that is still working in agriculture, and more. The data from European Investment Bank shows that the EU has still a lower rate of digitalization than the US. The best-performing countries in Europe in terms of digitalization are the Czech Republic, the Netherlands, and Finland. These three countries mentioned are even over the US the report shows. Romania is quoted in the moderate digitalization index with Bulgaria, Hungary, and France. The main issue in Romania is still the low rate of digital adoption among Romanian companies. The most-reported obstacle is lack of a skilled workforce and labor market regulations. Compared to other European countries where the lack of access to digital infrastructure is the main problem. The same publication also argues that almost $65 \%$ of digital firms reportedly increased the number of employees. (European Investment Bank, 2020) Regarding access to the internet, Romania has a big advantage being one of the countries with a very good internet speed, compared to other European countries - being in the top 5 globally for the Fixed Broadband speed and 38th for the mobile internet speed (SPEEDTEST, 2021). 


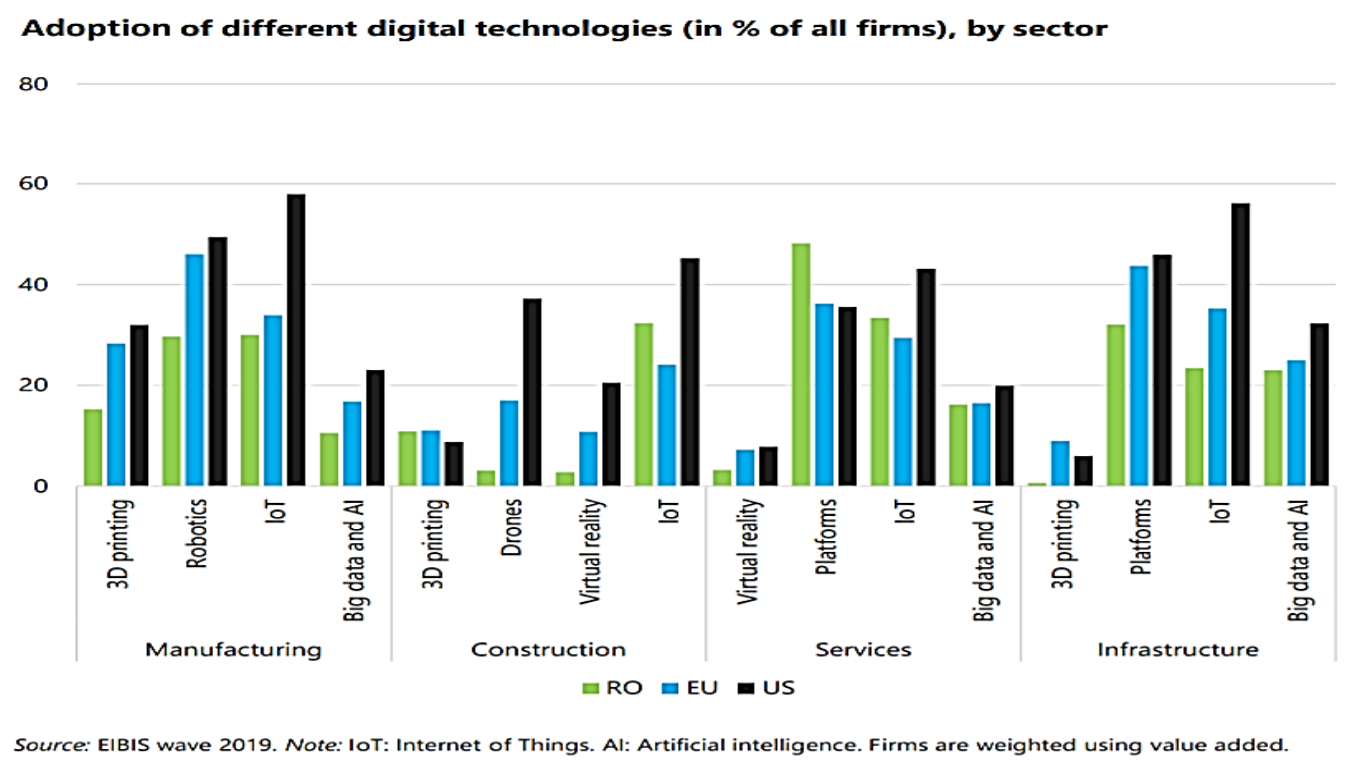

Figure 6. Adoption of different digital technologies (in \% of all firms), by sector

Source: European Investment Bank, 2020.

\section{Methodology}

This paper uses the comparative methods between using of the internet in agriculture and the lack of it, by putting into focus the newly discovered technologies, and what they bring to the table. It highlights the advantages and describes what stands behind it. It brings into light the new breakthrough technologies discovered and what they promise to deliver. The demonstration is made by comparing the use of IoT - the results and the lack of it. The data was processed with excel; the data was extracted using the representativeness criteria - the indicators that propagate the most onto the subject. The data was then analyzed and presented in the scenario case study using four different scenario-based situations where the use of the internet of things was augmented and the need was theoretically proven.

\section{Results and discussions}

\section{Scenario case study}

As climate changes, the drought phenomenon is more and more visible even in countries that did not use to face this type of change. Dryness is a current issue for current times, the drought crisis states that extreme droughts are showing worldwide. This puts immense pressure on food production, wetlands, cities, and almost 55 million people every year (WWF Germany, 2019). As the reports from Climate argue, more than 3 percent of the global land area was impacted by drought in every month of 2017 (Michon \& Lindsey 2018). In figure 7 below it is shown by Michon $\&$ Lindsey the regional temperatures, and precipitation data. Dry is marked with brown, whilst wet is in shades of blue/green. As it is visible, Romania has very big drought conditions, therefore the applicability of the IoT-humidity sensors and weather changing sensors could possibly make a remarkable difference.

In the study case below, the use case will be proven. The scenario case study has a choice of four different lands, to cover a broad range of most encountered situations. 


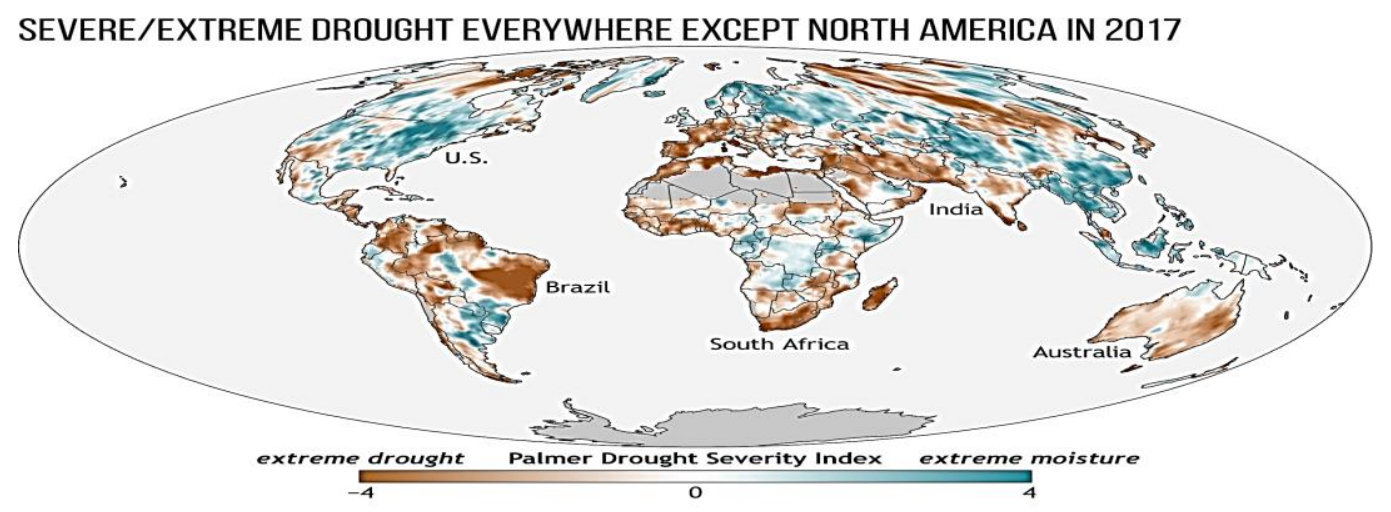

AREAS OF EXTREME DROUGHT ABOVE AVERAGE IN 2017

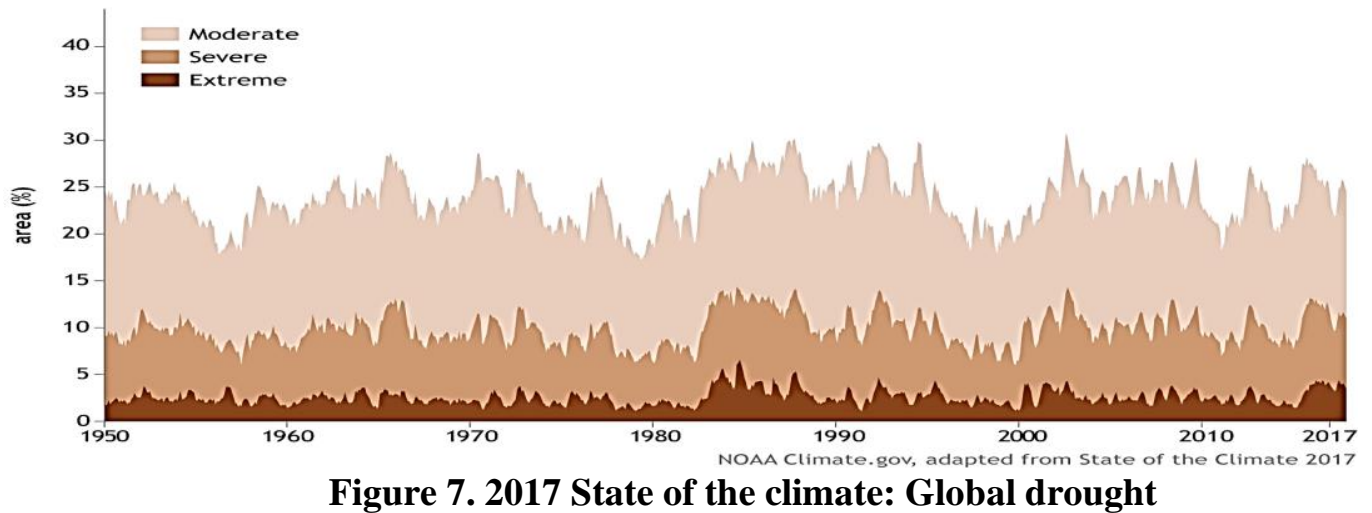

Figure 7. 2017 State of the climate: Global drought

Source: 2017 State of the climate: Global drought, https://www.climate.gov/news-features/featured-images/2017-state-climate-global-drought.

\section{The chosen landform is plain with middle-range rain levels - in the first situation.}

In the optimal situation - with green, it rains as much as it is needed and there is no need for irrigation. This means that the rain debits will be in the range needed by the farmers and will also happen at the desirable timings when the growth spurs are happening. To further add to this, the possibility of perfect timing between rain and crops is very low, this situation being the ideal one, the one that by using technology, the entrepreneurs strive to obtain it.

The best possible outcome for this scenario is that the crops are harvested timely and have the desired humidity, it does not rain outside the two mentioned ranges. The harvest is sold immediately, profit is collected.

\section{The chosen landform is plain with higher rain levels.}

In the second situation, it does rain as it is needed but, it also rains outside desired ranges, hence the humidity when harvesting is not the desired one, and the harvest must be set to dry in storage. The probability of this scenario is also low to medium, as farmers will not plant crops that have a certain need of rain and water and the landform cannot possibly provide it naturally. But for the highlighting purposes, this situation will be considered, to underline what good technology and irrigation sensors can provide. In this scenario, the farmer can plant crops without the restraints of rainwater debits. When the second scenario happens, without technological intervention, the consequence here is that the farmer needs storage, the harvest cannot be sold at the harvesting moment, hence the profit cannot be immediately collected. 


\section{The chosen landform is plain with low rain levels.}

In the third situation, it does not rain as needed, but it rains outside desired ranges. The harvest is smaller and when harvesting time comes, the humidity is also outside the range, therefore the need for additional storage costs. In this scenario same as the second scenario, the farmer must face the restrains of the weather and rainfall. In a world that needs food, this is not the best solution to follow when profit is desired. A secondary outcome is that the farmer is restrained in what crops to plant and when to plant them. But with the help of technology the spectra of plants that can be grown, broadens.

4. The chosen landform is plain with very low to absent rain levels. (dry phenomena encountered) In the fourth situation, it does not rain as needed, the crops' growth rate is below levels, hence a smaller harvest. The probability for this scenario to happen is medium to high, as many of the world's countries are affected by drought phenomena over the past year, and after specialist prediction, this will regress.

IoT in the optimal situation has use for precision agriculture, monitoring, and balancing if needed.

In the second situation, monitorization of the water levels in the soil is needed and weather changes - sudden weather changes. This gives time to the farmer to harvest sooner or later depending on the lack of desire for rain.

In the third situation not having water when crops are in the critical growth phases can even mean for some farmers the loss of the harvest, totally or partially. The given situation is like this, it does not rain when the critical phases are happening, but it rains when is time for harvest. The IoT with the sensors can prevent dryness and provide water when needed and the advanced weather monitoring system can help the farmer choose the best time for the harvest, rushing it or delaying it. The last part applies also to the fourth situation, where IoT sensors can help with a long period of dryness or what is also known as dry years.

As the research showed, the benefits of the Internet of Things are that not only farmers and entrepreneurs all over the world can see how the machines, crops etc. are used but also how can oneself find, then pursue the best machinery, the best product and how to find the best information to gain profit. Real-time data that are collected in the vast online databases - either we talk about social media or search engines, the data is constantly updated. A farmer can present their own experience in social media, and another one that is following it can see if its methods were successful and then can implement them himself. The most stunning thing is that not only you can access this information from fellow colleagues, but from others all around the world. What was little accessible - libraries and books, courses, classes etc. now is one click away. For a monthly subscription fee, one can access and download online libraries, have customized advice, and see real-time data. The future is cooperation, in a technologized world, where you can read reviews and feedbacks for the machines you are planning to buy. For juniors in this field, not going blindly and having live data is a breakthrough technology itself. As for the problem of digital skills, most of the technology developers are changing to user-adapted experience to make it more facile, having AI - artificial intelligence that crosses the barrier between user and software and makes everything smoother. An example of this is autonomous drones. To further argue, the technology today is user-based, and all over the world are teams dedicated to user experience enhancement. 


\section{Conclusion}

As new challenges arise - providing food with less and less available land, as the population will grow to almost 50 billion by 2050, the IOT can help with the use of fewer and fewer resources by having precision machinery that reduces waste. The changes in the weather can be predicted almost a few hours before, the farmer is notified by a mobile application on his phone (Suporn et al., 2015).

Internet of Things can provide real-time data between many subjects of interest and what

PICBE |

582 is more to it, is that it connects them, analyses the data then gives the client the output. It can help to raise precision and efficiency in many areas, reducing waste. Using the AI to recognize the weeds in the field is a precision agriculture revolution, the main outcome is reducing the surface of applying pest repellents - those were applied on the whole crop field, now can be focused just on the weeds thanks to weed recognizing devices. This is a healthier and sustainable approach to pest repelling.

By having real-time data, a farmer can increase and/or decrease the water consumption, usage of chemicals, the distance between crops, crop harvesting - by establishing the right timing to harvest, based on humidity and other chosen criteria. This surely opens the path to a more competitive and well-informed world of producers and a more informed market. Meaning that technology not only gave us the means to obtain the most profitable outcome but also gave everyone else the means to obtain the most profitable outcome. As the final reports from the seminar for digital farming that took place in Spain in 2020 February reveal that the implementation and tools can really help the farmers to develop the skills, they need to have a more fruitful transition toward more digital agriculture (EIP-AGRI, 2020). Romania has the potential of achieving fully digitalization in agriculture, one of the advantages is the internet speed - Romania being the 4th globally in terms of Fixed Broadband speed and $38^{\text {th }}$ in mobile internet speed (SPEEDTEST, 2021). In the future Romanians in the research field and not only, the focus should also be developing and engaging in new technologies. Having the digitalization and the technology to our side, even the most inexperienced people can start and obtain profit immediately. Focusing on the new ways to use tech in agriculture should be the main goal for this century, not only for profit but for growing crops and providing food sustainably.

\section{References}

Tzounis, A., Katsoulas, N., Bartzanas, T., \& Kittas, C. (2017).

Internet of Things in agriculture, recent advances and future challenges, Biosystems Engineering, Biosystems Engineering, 164, 31-48.

Benoit, A., Schroeder, A., \& Grimaudo, J. (2012). IT as enabler of sustainable farming: An empirical analysis of farmers' adoption decision of precision agriculture technology, Decision Support Systems, 54(1), 510-520.

Dermody, J. (2013). Social media connects farmers with suppliers and customers, The Irish Examiner.

EC Europe (2018). Drones in agriculture. Digital Transformation Monitor, Retrieved from https:// ec.europa.eu/growth/tools-databases/dem/monitor/sites/default/files/Drones_vf.pdf.

EC Europe (2020). Agriculture statistics at regional level, Retrieved from https://ec.europa.eu/ eurostat/statistics-explained/pdfscache/14247.pdf. 
EIP-AGRI (2020). New skills for digital farming. EIP-AGRI Workshop Aranjuez 5-6 February 2020, Retrieved from https://ec.europa.eu/eip/agriculture/sites/agri-eip/files/eip-agri_ seminar_new_skills_for_digital_farming_final_report_en_2020.pdf.

European Investment Bank (2020) Who is prepared for the new digital age? - Evidence from the EIB Investment Survey, Retrieved from https://www.eib.org/en/publications/who-isprepared-for-the-new-digital-age.htm.

Eurostat (2021) Farm indicators by agricultural area, type of farm, standard output, sex and age of the manager and NUTS 2 regions, Retrieved from https://appsso.eurostat.ec.europa. eu/nui/show.do?dataset=ef_m_farmang\&lang=en.

Eurostat (2021) Employees by sex, age and economic activity, Retrieved from http://appsso. eurostat.ec.europa.eu/nui/show.do?dataset=lfsq_eegan2\&lang=en.

Eurostat (2021) Individuals' level of digital skills, Retrieved from https://appsso.eurostat. ec.europa.eu/nui/show.do?dataset=isoc_sk_dskl_i\&lang=en.

Michon, S., Lindsey, R. (2018). 2017 State of the climate: Global drought, Climate news, stories, images, \& video (ClimateWatch Magazine), Retrieved from https://www.climate.gov/ news-features/featured-images/2017-state-climate-global-drought.

Padwick, C. (2020). AI for AG: Production machine learning for agriculture. PyTorch, Retrieved from https://medium.com/pytorch/ai-for-ag-production-machine-learning-for-agriculturee8cfdb9849a1.

O'Dea, S. (2020). Number of mobile devices worldwide 2020-2024, Retrieved from https://www. statista.com/statistics/245501/multiple-mobile-device-ownership-worldwide/.

Suporn, P., Pimwadee, C., \& Navaporn, S. (2015). Applications of Smartphone-Based Sensors in Agriculture: A Systematic Review of Research, Journal of Sensors, 1-18.

Sourcetrace (2020). How mobile apps are helping agriculture in achieving sustainable development?, Retrieved from https://www.sourcetrace.com/blog/mobile-apps-foragri culture/.

SPEEDTEST (2021). Global Speeds January 2021, Retrieved from https://www.speedtest.net/ global-index.

Zarnescu, A. (2019). In agriculture we currently monitor 38,000 hectares of land through IoT solutions in Romania. ZF High-Tech Innovation Summit 2019, Retrieved from https://www. zf.ro/business-hi-tech/adrian-zarnescu-cto-syswin-solutions-in-agricultura-monitorizamla-ora-actuala-38-000-de-hectare-de-teren-prin-solutii-iot-in-romania-18508462.

Willett, W.C., Stampfer, MJ. (2013). Current evidence on healthy eating, Annual Rev Public Health, 2013; 34:77-95. doi:10.1146/annurev-publhealth-031811-124646, Retrieved from https://pubmed.ncbi.nlm.nih.gov/23297654/.

WWF Germany (2019). Worsening drought risk impacts 55 million people every year, says WWF report. WWF Germany Report 2019. Retrieved from https://wwf.panda.org/discover/ our_focus/freshwater_practice/?352050/Worsening-drought-risk-impacts-55-millionpeople-every-year-says-WWF-report\#: :text=According\%20to\%20Drought $\% 20 \mathrm{Crisis} \%$ $3 \mathrm{~A} \% 20$ The,million\%20very\%20year\%20on\%20average. 